\title{
Role Of Vitamin K Therapy In Prevention Of Vascular Calcification In Chronic Kidney Disease
}

\author{
Mohamed Farouk Ibrahim Mosa and Ahmed Kamal Harfoosh
}

\begin{abstract}
Introduction: Matrix Gla protein (MGP) is a central calcification inhibitor of vascular wall. The biological activation of the calcification-inhibitory protein MGP can be achieved by simple administration of oral vitamin $K$.

Aim: The study was conducted to assess the effect of vitamin $k$ supplementation on vascular calcification and to evaluate its effect on MGA in hemodialysis patients.

Materials and Methods: Forty adult patients with end stage renal disease (ESRD) on regular hemodialysis sessions, thrice weekly, were enrolled in the study and were randomly assigned into two groups. Vitamin $\mathrm{K}$ group consisted of 20 patients were given oral vitamin $\mathrm{K}$ at $10 \mathrm{mg}$ after each session of dialysis for a duration of one year. No-Vitamin $\mathrm{K}$ group included 20 patients didn't receive vitamin $K$. All patients were subjected to the following: Matrix Gla protein (MGP), in addition to, plain digital abdominal $x$-ray and doppler ultrasound.

Results: After one-year of vitamin $\mathrm{K}$ supplementation, a significant increase in MGP levels in Vitamin K group (75.7 \pm 26 $\mathrm{ng} / \mathrm{mL}$ ) were noticed. There were no significant changes in CIMT and AACS in Vitamin $K$ group after vitamin $K$ supplementation in compared to their baseline levels, while the CIMT and AACS were significantly increased in No-Vitamin $K$ group in compared to their baseline levels.

Conclusion: Vitamin $\mathrm{K}$ supplementation could not stop vascular calcifications but significantly attenuate their progression.
\end{abstract}

Index Terms - CKD, Vascular calcification, Vitamin $\mathrm{K}$ supplementation.

\section{INTRODUCTION}

Vascular calcification (VC) represents an independent risk factor for cardiovascular disease in hemodialysis patients [1]. In the general population, classical atherosclerotic endpoints such as stroke or myocardial infarction are the dominant cause of death. Importantly, CKD patients mostly die from sudden cardiac death or ischemic heart disease due to premature vascular and cardiac aging [2]. Vascular calcification is highly prevalent in ESKD and independently predictive of future cardiovascular events and mortality [3]. Vascular calcification is an active cell-mediated process involving vascular smooth muscle cells (VSMC) apoptosis and vesicle release, a shift in the balance of inhibitors and promoters of vascular calcification, and VSMC differentiation from a contractile to osteochondrogenic phenotype [4], [5]. Calcification can occur in both the intimal and medial layers of vasculature, but medial calcification is the major form in

Published on July 6, 2020.

Mohamed Farouk Ibrahim Mosa, Azhar University, Egypt.

(corresponding e-mail: Faroukmohamed301@ yahoo.com)

Ahmed Kamal Harfoosh, AL-Azhar University, Egypt.
ESKD. Medial calcification increases large elastic artery stiffness and pulse-pressure, promotes left ventricular hypertrophy, reduces perfusion of the coronary arteries, and ultimately promotes increased cardiovascular mortality via increased risk of myocardial infarction and heart failure [3].

Matrix Gla protein (MGP) is a central calcification inhibitor. It is produced by vascular smooth muscle cells and requires vitamin K-dependent post-translational modification, namely gamma carboxylation, to be fully active [6]. Uncarboxylated MGP, formed because of vitamin $\mathrm{K}$ deficiency, is associated with cardiovascular diseases. It has become evident that a high prevalence of subclinical vitamin $\mathrm{K}$ deficiency exists in hemodialysis patients [7]. MGP is an extracellular matrix protein that accumulates near the borders of calcified plaques [8]. It is progressively expressed during osteoblastic differentiation of VSMC [9], and vascular pericytes [10]. Paradoxically, MGP-deficient mice have extensive arterial calcification, aortic dissection, and death at 6-8 weeks [11]. Conversely, MGP transgenic mice have reduced calcification as well as reduced atherosclerosis [12]. MGP requires vitamin K-dependent gamma-carboxylation. Inhibiting gamma-carboxylation of MGP by warfarin reduces its ability to inhibit matrix mineralization, possibly through inhibiting binding to potent osteogenic factor, bone morphogenetic protein [13]. This may account for the induction of vascular calcification by the vitamin $\mathrm{K}$ inhibitor, warfarin, in rodents [14]. The present study was conducted to assess the effect of vitamin $\mathrm{k}$ supplementation on vascular calcification and to evaluate its effect on MGA in hemodialysis patients.

\section{MATERIALS AND MethodS}

The study was carried out for a period of one year from March 2018 to April 2019 at - EL-HUSSIEN hospital faculty of medicine Al-azhar University. A total 40 clinically stable end stage kidney disease patients in addition to 20 healthy volunteers as a control group were enrolled in this prospective study. All patients were dialyzed via arteriovenous fistula three times a week for four hours' session using polysulfone low flux dialyzer $1.6 \mathrm{~m} 2$ surface area, with dialysate flow $500 \mathrm{ml} / \mathrm{min}$ and dialysate calcium concentration $1.25 \mathrm{mmol} / \mathrm{l}$, using heparin as anticoagulant with tailored doses according to each case and bicarbonate based dialysate. The adequacy of dialysis was assessed using $\mathrm{Kt} / \mathrm{V}$ formula ( $\mathrm{K}$ is patient clearance, $\mathrm{t}$ dialysis time, $\mathrm{V}$ urea space) [15]. Patients older than 25 years who have maintained on regular hemodialysis for more than one year were included in the study. While, patients with history of thrombosis, inflammatory bowel disease, diabetes mellitus, liver dysfunction or coagulation disorders, in addition to 
patients received vitamin $\mathrm{K}$ antagonists were excluded.

The patients were randomly assigned into two groups. Vitamin K group consisted of 20 patients (11 males and 9 females, mean age was 52.1 \pm 7.52 years) received oral vitamin $\mathrm{K}$ (Phytomenadione $10 \mathrm{mg}$ ) after each session of dialysis for a duration of one year. No vitamin K group included 20 patients ( 7 males and 13 females, mean age was $48.3 \pm 9.33$ years) didn't receive vitamin K. All patients were subjected to the following: Hemoglobin level, serum creatinine, blood urea, serum phosphorus, total serum calcium, intact parathormone (iPTH), lipid profile and MGP. Serum MGP was determined using sandwich enzyme immunoassay supplied from The Life Science Company (2BScientific Ltd, Cherwell Innovation Centre, 77 Heyford Park, Upper Heyford, UK) [16]. In addition to, lateral abdominal $\mathrm{x}$-radiography of the aorta to measure abdominal aorta calcification score (AACS) using a validated 24-point abdominal aortic calcification score [17] and doppler ultrasound for assessment of carotid intimal medial thickness (CIMT). All patients were informed about the content of the study and gave their written approvals before enrollment. All procedures were performed in accordance with the ethical standards of EL-HUSSEIN HOSPITAL University's committee on human experiments.

\section{A. Statistical Methods}

The statistical analysis was performed by using SPSS version 18.0 statistical software (SPSS Inc., Chicago, IL, USA). The results were indicated by mean \pm standard deviation. Paired-samples t - test was used in comparing the results at baseline, after one year. Independent-samples test was used in comparing independent samples. For qualitative data, the number and percent distribution was calculated, chi square $(\chi 2)$ was used as test of significance. Significant difference was $\mathrm{p}<0.05$.

\section{RESULTS}

Characteristics of the study participants are shown in Table I, II. The level of MGP in ESKD patients was $50 \pm 10.8 \mathrm{ng} / \mathrm{mL}$. This level was more than 2 times higher than that of a matched control group $(23 \pm 3.9 \mathrm{ng} / \mathrm{mL})$ without kidney disease. All ESKD patients had significantly higher PTH level $(434 \pm 471 \mathrm{pg} / \mathrm{ml})$, triglycerides level $(172 \pm$ $88 \mathrm{mg} / \mathrm{dl})$, carotid intima media thickness $(0.84 \pm 0.20 \mathrm{~mm}$, $0.85 \pm 0.21 \mathrm{~mm}$ for left and right CIMT respectively) and significantly lower HDL and hemoglobin level $(9.9 \pm 2 \mathrm{~g} / \mathrm{dl})$ than that of a matched control group (Table I).

The baseline biochemical and radiological findings of the Vitamin $\mathrm{K}$ and No-Vitamin $\mathrm{K}$ groups were a like comparable and are shown in Table II. There was a significant increase in MGP levels in the Vitamin $\mathrm{K}$ group $(75.7 \pm 26 \mathrm{ng} / \mathrm{mL})$ after vitamin $\mathrm{K}$ supplementation compared to its baseline levels $(51.49 \pm 12 \mathrm{ng} / \mathrm{mL})$. On the contrary, the changes in CIMT and AACS were not statistically significant in vitamin $\mathrm{K}$ group in compared to their baseline levels Table III. Moreover, there were significant increase in AACS and CIMT in patients who did not receive vitamin $\mathrm{K}$ supplementation (Table III).
TABLE I: COMPARISON BETWEEN ESKD PATIENTS AND CONTROL GROUP

\begin{tabular}{|c|c|c|c|c|c|c|}
\hline & \multicolumn{2}{|c|}{ ESKD } & \multicolumn{3}{|c|}{ Control } \\
\hline & & Mean & $\pm \mathrm{SD}$ & Mean & $\pm \mathrm{SD}$ & \\
\hline \multicolumn{2}{|c|}{ Age (year) } & 50.2 & 8.5 & 47 & 8 & $>0.05$ \\
\hline \multirow{2}{*}{ Sex } & Male $\mathrm{n} / \%$ & \multicolumn{2}{|c|}{$18 / 45 \%$} & \multicolumn{2}{|c|}{$22 / 55 \%$} & \multirow{2}{*}{$>0.05$} \\
\hline & Female $\mathrm{n} / \%$ & \multicolumn{2}{|c|}{$13 / 65 \%$} & \multicolumn{2}{|c|}{$7 / 35 \%$} & \\
\hline \multicolumn{2}{|c|}{ BMI $\left(\mathrm{kg} / \mathrm{m}^{2}\right)$} & 27 & 5.5 & 25 & 3.8 & $>0.05$ \\
\hline \multicolumn{2}{|c|}{ Calcium (mg/dl) } & 8.6 & 1 & 9 & 0.6 & $>0.05$ \\
\hline \multicolumn{2}{|c|}{ Phosphorus (mg/dl) } & 5.3 & 1.2 & 4.1 & 0.5 & $<0.05$ \\
\hline \multicolumn{2}{|c|}{ PTH (pg/ml) } & 434 & 471 & 24.7 & 9 & $<0.005$ \\
\hline \multicolumn{2}{|c|}{ Cholesterol (mg/dl) } & 148 & 30 & 142 & 33 & $>0.05$ \\
\hline \multicolumn{2}{|c|}{ LDL (mg/dl) } & 126 & 19 & 122 & 15 & $>0.05$ \\
\hline \multicolumn{2}{|c|}{ HDL (mg/dl) } & 39 & 5.6 & 43.8 & 6.1 & $<0.05$ \\
\hline \multicolumn{2}{|c|}{ Triglyceride $(\mathrm{mg} / \mathrm{dl})$} & 172 & 88 & 128 & 45 & $<0.05$ \\
\hline \multicolumn{2}{|c|}{ Blood urea (mg/dl) } & 152 & 41 & 24 & 5.9 & $<0.005$ \\
\hline \multicolumn{2}{|c|}{ Creatinine (mg/dl) } & 11 & 2.5 & 0.70 & 0.12 & $<0.005$ \\
\hline \multicolumn{2}{|c|}{ Haemoglobin g/dl } & 9.9 & 2 & 12.6 & 1.1 & $<0.005$ \\
\hline \multicolumn{2}{|c|}{ MGP (pg/ml) } & 50 & 10.8 & 23 & 3.9 & $<0.005$ \\
\hline \multicolumn{2}{|c|}{ Lt CIMT (mm) } & 0.84 & 0.20 & 0.59 & 0.12 & $<0.005$ \\
\hline \multicolumn{2}{|c|}{ Rt CIMT (mm) } & 0.85 & 0.21 & 0.61 & 0.10 & $<0.005$ \\
\hline
\end{tabular}

ESKD: end stage kidney disease, BMI: body mass index, PTH: parathyroid hormone, LDL: low density lipoprotein, HDL: high density lipoprotein, AACS: abdominal aorta calcification score, Lt. CIMT: left carotid intima media thickness Rt.CIMT: right carotid intima media thickness, MGP: Matrix gla protein.

TABLE II: COMPARISON BETWEEN VITAMIN K GROUP AND NO-VITAMIN K GROUP AT THE START OF THE STUDY

\begin{tabular}{|c|c|c|c|c|}
\hline \multicolumn{2}{|r|}{ Parameters } & $\begin{array}{l}\text { Vitamin K } \\
\text { group } \\
(\mathrm{M} \pm \mathrm{SD})\end{array}$ & $\begin{array}{c}\text { No-vitamin } \\
\text { K group } \\
(\mathrm{M} \pm \mathrm{SD})\end{array}$ & $\mathrm{P}$ value \\
\hline \multicolumn{2}{|r|}{ Age/years } & $51 \pm 7$ & $48 \pm 9$ & $>0.05$ \\
\hline \multirow{2}{*}{ Sex } & Male $\mathrm{n} / \%$ & \multicolumn{2}{|c|}{$11 / 55 \%$} & $>0.05$ \\
\hline & Female n/\% & \multicolumn{2}{|c|}{$9 / 45 \%$} & $>0.05$ \\
\hline \multicolumn{2}{|c|}{ BMI $\left(\mathrm{kg} / \mathrm{m}^{2}\right)$} & $26.9 \pm 6$ & $24 \pm 4.7$ & $>0.05$ \\
\hline \multicolumn{2}{|c|}{$\begin{array}{l}\text { Duration of hemodialysis } \\
\text { (months) }\end{array}$} & $74 \pm 41$ & $87 \pm 46$ & $>0.05$ \\
\hline \multicolumn{2}{|c|}{ Calcium (mg/dl) } & $8.6 \pm 1.7$ & $8.6 \pm 0.8$ & $>0.05$ \\
\hline \multicolumn{2}{|c|}{ Phosphorus (mg/dl) } & $5.4 \pm 1.4$ & $5.2 \pm 0.9$ & $>0.05$ \\
\hline \multicolumn{2}{|c|}{ PTH (pg/ml) } & $486.95 \pm 627$ & $340 \pm 227$ & $>0.05$ \\
\hline \multicolumn{2}{|c|}{ Cholesterol (mg/dl) } & $152 \pm 26.7$ & $155 \pm 33$ & $>0.05$ \\
\hline \multicolumn{2}{|c|}{ LDL (mg/dl) } & $125 \pm 20$ & $128 \pm 18$ & $>0.05$ \\
\hline \multicolumn{2}{|c|}{$\mathrm{HDL}(\mathrm{mg} / \mathrm{dl})$} & $39 \pm 5.7$ & $40 \pm 5.7$ & $>0.05$ \\
\hline \multicolumn{2}{|c|}{ Triglyceride $(\mathrm{mg} / \mathrm{dl})$} & $166.8 \pm 82$ & $177 \pm 93$ & $>0.05$ \\
\hline \multicolumn{2}{|c|}{ Blood urea (mg/dl) } & $152 \pm 42$ & $142 \pm 38.5$ & $>0.05$ \\
\hline \multicolumn{2}{|c|}{ Creatinine $(\mathrm{mg} / \mathrm{dl})$} & $11.8 \pm 3$ & $10.4 \pm 1.8$ & $>0.05$ \\
\hline \multicolumn{2}{|c|}{ Haemoglobin g/dl } & $10 \pm 4.5$ & $9.6 \pm 2.3$ & $>0.05$ \\
\hline \multicolumn{2}{|c|}{ AACS } & $5.9 \pm 2.5$ & $5.95 \pm 2.4$ & $>0.05$ \\
\hline \multicolumn{2}{|c|}{ Lt. CIMT (mm) } & $0.81 \pm 0.20$ & $0.88 \pm 0.19$ & $>0.05$ \\
\hline \multicolumn{2}{|c|}{ Rt. CIMT (mm) } & $0.82 \pm 0.22$ & $0.88 \pm 0.2$ & $>0.05$ \\
\hline \multicolumn{2}{|c|}{ MGP (pg/ml) } & $50.49 \pm 12$ & $46.56 \pm 8.7$ & $>0.05$ \\
\hline
\end{tabular}

BMI: body mass index, PTH: parathyroid hormone, LDL: low density lipoprotein, HDL: high density lipoprotein, AACS: abdominal aorta calcification score, Lt. CIMT: left carotid intima media thickness Rt.CIMT: right carotid intima media thickness, MGP: Matrix gla protein.

The comparison between Vitamin K and No-Vitamin K groups after one year of vitamin $\mathrm{K}$ supplementation revealed that high significant increase of MGP $(75.76 \pm 26 \mathrm{pg} / \mathrm{dl})$ in Vitamin $\mathrm{K}$ group in compare to No-Vitamin $\mathrm{K}$ group $(49.36 \pm 6 \mathrm{pg} / \mathrm{dl}) \mathrm{P}<0.005$. Moreover, there were significant increase in AACS and CIMT in No-Vitamin K in compare to Vitamin K group (Table IV).

MGP was directly correlated with serum phosphate, iPTH, blood urea, serum creatinine, cholesterol level, LDL and triglyceride level. In addition, MGP was inversely correlated with duration of hemodialysis, HDL, hemoglobin levels and AACS (Table V). 
TABLE III: COMPARISON BETWEEN LABORATORY AND RADIOLOGICAL FINDINGS OF STUDIED GROUPS AT THE START AND AFTER ONE YEAR OF VITAMIN K TREATMENT

\begin{tabular}{|c|c|c|c|c|c|}
\hline \multicolumn{2}{|c|}{ Parameters } & $\begin{array}{l}\text { Vitamin K group } \\
\qquad(\mathrm{M} \pm \mathrm{SD})\end{array}$ & $\mathrm{P}$ value & $\begin{array}{l}\text { No-vitamin K group } \\
\qquad(\mathrm{M} \pm \mathrm{SD}\end{array}$ & $P$ value \\
\hline \multirow{2}{*}{$\mathrm{BMI}\left(\mathrm{kg} / \mathrm{m}^{2}\right)$} & At start & $26.9 \pm 6$ & \multirow{2}{*}{$>0.05$} & $24 \pm 4.7$ & \multirow{2}{*}{$>0.05$} \\
\hline & After 1 year & $24.8 \pm 4.5$ & & $25.2 \pm 3.4$ & \\
\hline \multirow{2}{*}{ Calcium (mg/dl) } & At start & $8.6 \pm 1.7$ & \multirow{2}{*}{$>0.05$} & $8.6 \pm .8$ & \multirow{2}{*}{$>0.05$} \\
\hline & After 1 year & $8.7 \pm 0.9$ & & $8.4 \pm 0.7$ & \\
\hline \multirow{2}{*}{ Phosphorus (mg/dl) } & At start & $5.4 \pm 1.4$ & \multirow{2}{*}{$>0.05$} & $5.2 \pm 0.9$ & \multirow{2}{*}{$>0.05$} \\
\hline & After 1 year & $5.3 \pm 1.3$ & & $5 \pm 1.7$ & \\
\hline \multirow{2}{*}{ PTH (pg/ml) } & At start & $486.95 \pm 627$ & \multirow{2}{*}{$>0.05$} & $340 \pm 227$ & \multirow{2}{*}{$>0.05$} \\
\hline & After 1 year & $496.80 \pm 491$ & & $466.5 \pm 391$ & \\
\hline \multirow{2}{*}{ Cholesterol (mg/dl) } & At start & $152 \pm 26.7$ & \multirow{2}{*}{$<0.05$} & $155 \pm 33$ & \multirow{2}{*}{$>0.05$} \\
\hline & After 1 year & $130 \pm 14$ & & $154 \pm 33$ & \\
\hline \multirow{2}{*}{$\mathrm{LDL}(\mathrm{mg} / \mathrm{dl})$} & At start & $125 \pm 20$ & \multirow{2}{*}{$>0.05$} & $128 \pm 18.6$ & \multirow{2}{*}{$>0.05$} \\
\hline & After 1 year & $131 \pm 21$ & & $136 \pm 17$ & \\
\hline \multirow{2}{*}{ HDL (mg/dl) } & At start & $39 \pm 5.7$ & \multirow{2}{*}{$>0.05$} & $40 \pm 5.7$ & \multirow{2}{*}{$>0.05$} \\
\hline & After 1 year & $40 \pm 6$ & & $37.6 \pm 3.4$ & \\
\hline \multirow{2}{*}{ Triglyceride (mg/dl) } & At start & $166.8 \pm 82$ & \multirow{2}{*}{$>0.05$} & $177 \pm 93$ & \multirow{2}{*}{$>0.05$} \\
\hline & After 1 year & $146 \pm 64$ & & $173 \pm 109$ & \\
\hline \multirow{2}{*}{ Blood urea (mg/dl) } & At start & $152 \pm 42$ & \multirow{2}{*}{$>0.05$} & $142 \pm 38.5$ & \multirow{2}{*}{$>0.05$} \\
\hline & After 1 year & $144 \pm 26$ & & $150 \pm 23$ & \\
\hline \multirow{2}{*}{ Creatinine (mg/dl) } & At start & $10.6 \pm 3$ & \multirow{2}{*}{$>0.05$} & $10.4 \pm 1.8$ & \multirow{2}{*}{$>0.05$} \\
\hline & After 1 year & $10.2 \pm 2$ & & $10.8 \pm 1.9$ & \\
\hline Hoemoglohin $g / d 1$ & At start & $10 \pm 4.5$ & $>005$ & $9.6 \pm 2.3$ & $>005$ \\
\hline Haemoglobin g/dl & After 1 year & $9.6 \pm 2$ & $>0.05$ & $9.6 \pm 2$ & $>0.05$ \\
\hline & At start & $5.9 \pm 2.5$ & & $5.95 \pm 2.4$ & \\
\hline AACS & After 1 year & $6 \pm 2.5$ & $>0.05$ & $7.2 \pm 2.2$ & $<0.005$ \\
\hline It CDMT (mm) & At start & $0.81 \pm 0.2$ & $>005$ & $0.88 \pm 0.19$ & $<0005$ \\
\hline Lt. CIMT (mm) & After 1 year & $0.82 \pm 0.22$ & $>0.05$ & $1.08 \pm 0.18$ & $<0.005$ \\
\hline & At start & $0.82 \pm 0.2$ & $>005$ & $.88 \pm 0.2$ & \\
\hline Rt. CIMT (mm) & After 1 year & $0.81 \pm 0.26$ & $>0.05$ & $1.03 \pm 0.17$ & $<0.005$ \\
\hline & At start & $50.49 \pm 12$ & & $46.56 \pm 8.7$ & \\
\hline MGP (pg/ml) & After 1 year & $74.76 \pm 26$ & $<0.05$ & $48.36 \pm 6$ & $>0.05$ \\
\hline
\end{tabular}

BMI: body mass index, PTH: parathyroid hormone, LDL: low density lipoprotein, HDL: high density lipoprotein, AACS: abdominal aorta calcification score, Lt. CIMT: left carotid intima media thickness Rt.CIMT: right carotid intima media thickness, MGP: Matrix gla protein.

TABLE IV: COMPARISON BETWEEN VITAMIN K GROUP AND NOVITAMIN K GROUP AS REGARDS LABORATORY AND RADIOLOGICAL FINDINGS AFTER ONE YEAR OF VITAMIN K SUPPLEMENTATION

\begin{tabular}{|c|c|c|c|}
\hline FRFR W Parameters & $\begin{array}{c}\text { Vitamin K } \\
\text { group } \\
\text { (Mean } \pm \text { SD) }\end{array}$ & $\begin{array}{c}\text { No-vitamin K } \\
\text { group } \\
\text { (Mean } \pm \text { SD) }\end{array}$ & P value \\
\hline BMI (kg/m²) & $24.8 \pm 4.5$ & $25.2 \pm 4.3$ & $>0.05$ \\
\hline Calcium (mg/dl) & $8.7 \pm 0.9$ & $8.4 \pm 0.7$ & $>0.05$ \\
\hline Phosphorus (mg/dl) & $5.3 \pm 1.3$ & $5 \pm 1.7$ & $>0.05$ \\
\hline PTH (pg/ml) & $496.8 \pm 491$ & $466.2 \pm 391$ & $>0.05$ \\
\hline Cholesterol (mg/dl) & $130 \pm 14$ & $154 \pm 34$ & $<0.05$ \\
\hline LDL (mg/dl) & $131 \pm 21$ & $136 \pm 17$ & $>0.05$ \\
\hline HDL (mg/dl) & $40 \pm 6$ & $37.6 \pm 3.4$ & $>0.05$ \\
\hline Triglyceride (mg/dl) & $146 \pm 64$ & $173 \pm 109$ & $>0.05$ \\
\hline Blood urea (mg/dl) & $154 \pm 26$ & $150 \pm 23$ & $>0.05$ \\
\hline Creatinine (mg/dl) & $10.2 \pm 2$ & $10.8 \pm 1.9$ & $>0.05$ \\
\hline Haemoglobin g/dl & $9.6 \pm 2$ & $9.6 \pm 2$ & $>0.05$ \\
\hline AACS & $6 \pm 2.5$ & $7.2 \pm 2.2$ & $>0.05$ \\
\hline Lt. CIMT (mm) & $0.82 \pm 0.22$ & $1.08 \pm 0.18$ & $<0.005$ \\
\hline Rt. CIMT (mm) & $0.81 \pm 0.26$ & $1.03 \pm 0.17$ & $<0.005$ \\
\hline MGP (pg/ml) & $74.76 \pm 26$ & $48.36 \pm 6$ & $<0.005$ \\
\hline
\end{tabular}

BMI: body mass index, PTH: parathyroid hormone, LDL: low density lipoprotein, HDL: high density lipoprotein, AACS: abdominal aorta calcification score, Lt. CIMT: left carotid intima media thickness Rt.CIMT: right carotid intima media thickness, MGP: Matrix gla protein.

\section{DISCUSSION}

In this study, we demonstrate that MGP plasma levels markedly elevated in hemodialysis patients compared with subjects with normal renal function. The association between ESRD and elevated MGP has been established by previous studies [18]-[20]. Increased production or release of MGP may be related to the generally increased vascular damage observed in dialysis patients, and indeed, an accumulation of MGP in and around vascular calcifications has been documented [18] Moreover, decreased MGP renal clearance could be attributed to reduced kidney function. In healthy subjects, MGP is not found in urine, but MGP levels in renal veins are reported to be $13 \%$ lower than in renal arteries [21]. Thus, the kidneys excrete and metabolize MGP, and some degree of renal retention will occur in dialysis patients.

It was found that most hemodialysis patients show subclinical vitamin $\mathrm{K}$ deficiency, it is possible explanation may be the recommended diet for hemodialysis patients, low potassium diet (green leafy vegetables) also is low in vitamin $\mathrm{K}$, and a diet low in phosphorus also is low in vitamin $\mathrm{K}$ content [22]. Observational clinical trials confirmed that low dietary intake of vitamin $\mathrm{K}$ was associated with cardiovascular risk and calcification. Also, Japanese survey among dialysis populations estimated this risk to be 11, fold higher compared with patients' not receiving vitamin $\mathrm{K}$ antagonists on the other hand, it was also demonstrated that there is a frequent nutritional vitamin $\mathrm{K}$ deficiency in hemodialysis patients [23]. Preventive action of vitamin $\mathrm{K}$ in vascular calcification has been proposed based on its role in activating MGP, a calcification inhibitor that is expressed in vascular tissue [24]. It was demonstrated that biological activation of the calcificationinhibitory protein MGP can be achieved by simple administration of oral vitamin $\mathrm{K}$. It was shown that supplementation of vitamin $\mathrm{K}$ is most likely superior to efforts aiming at increasing the nutritional intake of vitamin $\mathrm{K}$ in dialysis patients [25]. 
TABLE V: CORRELATION BETWEEN MATRIX GLA PROTEIN AND TESTED VARIABLES

\begin{tabular}{|c|c|c|c|c|c|c|c|c|}
\hline & \multicolumn{2}{|c|}{ MGP } & \multicolumn{2}{|c|}{ AACS } & \multicolumn{2}{|c|}{ Lt CIMT } & \multicolumn{2}{|c|}{ Rt CIMT } \\
\hline & $\mathrm{R}$ & $\mathrm{P}$ & $\mathrm{r}$ & $\mathrm{P}$ & $\mathrm{r}$ & $\mathrm{P}$ & $\mathrm{r}$ & $\mathrm{P}$ \\
\hline Age (year) & 0.083 & 0.528 & 0.209 & 0.195 & 0.124 & 0.343 & 0.057 & 0.663 \\
\hline BMI $\left(\mathrm{kg} / \mathrm{m}^{2}\right)$ & 0.117 & 0.373 & -0.063 & 0.700 & -0.017 & 0.896 & -0.065 & 0.620 \\
\hline Duration of hemodialysis & -0.393 & 0.012 & 0.580 & 0.000 & 0.218 & 0.176 & 0.305 & 0.056 \\
\hline Serum calcium (mg/dl) & -0.221 & 0.090 & -0.023 & 0.888 & -0.254 & 0.050 & -0.155 & 0.236 \\
\hline Serum phosphorus $(\mathrm{mg} / \mathrm{dl})$ & 0.322 & 0.012 & 0.306 & 0.055 & 0.530 & 0.000 & 0.509 & 0.000 \\
\hline $\mathrm{iPTH}(\mathrm{pg} / \mathrm{dl})$ & 0.334 & 0.009 & 0.259 & 0.106 & 0.401 & 0.001 & 0.401 & 0.001 \\
\hline Cholesterol (mg/dl) & 0.256 & 0.048 & -0.234 & 0.146 & -0.021 & 0.872 & 0.094 & 0.473 \\
\hline LDL (mg/dl) & 0.308 & 0.017 & -0.190 & 0.241 & 0.113 & 0.388 & 0.140 & 0.286 \\
\hline HDL (mg/dl) & -0.394 & 0.002 & 0.048 & 0.770 & -0.216 & 0.097 & -0.187 & 0.154 \\
\hline Triglyceride (mg/dl) & 0.299 & 0.020 & -0.086 & 0.596 & 0.344 & 0.007 & 0.266 & 0.040 \\
\hline Blood urea $(\mathrm{mg} / \mathrm{dl})$ & 0.688 & 0.000 & 0.053 & 0.747 & 0.436 & 0.001 & 0.360 & 0.005 \\
\hline Serum creatinine (mg/dl) & 0.775 & 0.000 & -0.042 & 0.796 & 0.445 & 0.000 & 0.375 & 0.003 \\
\hline Haemoglobin (g/dl) & -0.486 & 0.000 & -0.085 & 0.603 & -0.383 & 0.003 & -0.359 & 0.005 \\
\hline AACS & -0.606 & 0.000 & 1 & & 0.595 & 0.000 & 0.586 & 0.000 \\
\hline Lt CIMT(mm) & 0.213 & 0.102 & 0.595 & 0.000 & 1 & & 0.912 & 0.000 \\
\hline Rt CIMT (mm) & 0.212 & 0.103 & 0.586 & 0.000 & 0.912 & 0.000 & 1 & \\
\hline
\end{tabular}

BMI: body mass index, PTH: parathyroid hormone, LDL: low density lipoprotein, HDL: high density lipoprotein, AACS: abdominal aorta calcification score, Lt. CIMT: left carotid intima media thickness Rt.CIMT: right carotid intima media thickness, MGP: Matrix gla protein.

In current study, hemodialysis patients who received oral vitamin $\mathrm{K}$ for one year have significant increase in the level of matrix gla protein (MGP) than hemodialysis patients who did not receive vitamin K. Similarly, many previous studies have demonstrated that daily supplementation of vitamin K led to a significant increase in MGP [26,] [27]. The combination of vitamin $\mathrm{K}$ and $\mathrm{D}$ is more effective in increasing MGP and preventing blood vessel calcification [28]-[30]. In contrast, low circulating MGP concentrations were associated with more vascular calcification [31]. MGP indeed exerts its function by binding to crystal nuclei in hydroxyapaptite or by inhibiting bone morphogenetic protein-2 However, both mechanisms of action MGP has to be carboxylated [24]. Phosphorylation plays an important role in the secretion of MGP. The protein sequence of MGP includes 9 glutamate residues, 5 of which need to be carboxylated to yield bioactive MGP [32]. In humans, carboxylated MGP has been detected in intact healthy vessels, whereas uncarboxylated MGP accumulates at sites of vascular calcification [33]. It was demonstrated that undercarboxylated MGP is abundantly present in atherosclerotic intima and in media sclerosis, suggesting that local vitamin $\mathrm{K}$ deficiency and impaired protection attributable to poor MGP carboxylation [32]. Interestingly, a recent study has found a 10- fold increase in MGP gene expression after vitamin $\mathrm{K}$ supplementation was recorded in animals. Since vitamin $\mathrm{K}$ has no reported side effects, authors concluded that it seems a promising therapeutic agent for CKD patients [34].

Carotid intima-media thickness (CIMT) is increasingly used as a surrogate marker for atherosclerosis, and it was shown that CIMT is a strong predictor of future vascular events such as myocardial infarction and stroke [35]. The association between CIMT and cardiovascular disease (CVD) has been demonstrated in a predialysis CKD population. The CIMT has been found to be a strong predictor of cardiovascular or all-cause mortality [36]. Moreover, patients on chronic haemodialysis suffer from extensive vascular calcifications (VC). The presence of $\mathrm{VC}$ is directly related to increased cardiovascular morbidity and mortality in the dialysis population and progression of VC provides independent incremental prognostic information [37]. Abdominal aortic calcification has a high prevalence in hemodialysis patients. Abdominal aortic calcification score (AACS) is an easy method to detect abdominal aortic calcification [17].

In the current study, CIMT was higher among ESKD patients than normal population and all the patients had evidence of abdominal aortic calcification. After one year, patients received vitamin $\mathrm{K}$ supplementation showed insignificant increase the CIMT and AACS, associated with significant increasing MGP. In contrary, the insignificant change in the levels of MGP associated with significant progressive increase in CIMT and AACS in patients did not received vitamin $\mathrm{K}$ supplementation. Such a meaningful change in CIMT and AACS after a relatively short treatment is very surprising. Over the past decade, a large body of evidence has accumulated establishing that vitamin $\mathrm{K}$ is essential for vascular health. Vitamin $\mathrm{K}$ supplementation may be a simple means to prevent progression of $\mathrm{VC}$ in haemodialysis patients, a population characterized by severe functional vitamin $\mathrm{K}$ deficiency. Conversely, Vitamin $\mathrm{K}$ antagonists have garnered attention as they may potentially aggravate progression of $\mathrm{VC}$ in dialysis patients [38]. Kurnatowska et al. [39] reported an increase in CIMT was significantly lower in the vitamin $\mathrm{K}$ treated patients with renal failure. Gast et al., found that high dietary intake of vitamin $\mathrm{K}$ may protect against the development of coronary heart disease [40]. The combination of vitamin $\mathrm{K}$ and $\mathrm{D}$ is more effective in decrease progression of coronary artery calcification [29]. The decrease in progression of coronary artery calcification is associated with increasing MGP among the patients who have received vitamin $\mathrm{K}$ vitamin supplementation [28]-[30].

Dyslipidaemia is a common disorder in ESRD patients. In CKD patients, total and LDL cholesterol concentrations frequently remain comparable with that of the general population, whereas increases in the TG concentrations and decreases in the HDL cholesterol are often seen [41]. Similarly, in current study total cholesterol and LDL cholesterol concentrations remain comparable to controls and increases in the TG concentrations and decreases in the HDL cholesterol are often seen in ESKD patients. Moreover, vitamin K supplementation for one year had decreased the level of cholesterol compared to those who did not receive vitamin $\mathrm{K}$, similar result has been obtained 
by Kawashima et al., [42] found that daily doses of vitamin $\mathrm{K}$ decreased the plasma levels of total cholesterol in the vitamin $\mathrm{K}$ treated patients compared to hypercholesterolemic control group. In addition, American Journal of Nursing 1998 reported that Japanese clinicians gave vitamin $\mathrm{K}$ to patients who had chronic renal failure and were being treated with continuous ambulatory peritoneal dialysis. Total cholesterol and triglycerides were measured. After administration of vitamin $\mathrm{K}$, total cholesterol concentrations were significantly lower than that before treatment. There were no significant changes in triglycerides during observation [43]. These results suggest that vitamin $\mathrm{K}$ may have a beneficial effect on total cholesterol concentrations. In the current study, MGP was directly correlated with serum phosphate, iPTH, blood urea, serum creatinine, cholesterol level, LDL and triglyceride level. In addition, MGP was inversely correlated with duration of hemodialysis, HDL, hemoglobin levels and AACS, and not related to age and body mass index (BMI). This were reported by previous studies [21], [31], [44]. Up till now there is no treatment to reverse vascular calcification in ESKD patients. The current clinical practice should focus on prevention and retardation of its progression [45]. The main limitation of current study is the small number of examined patients resulting in weakening of the statistical power. A second, is the method we applied to evaluate the arterial calcifications. Classic radiography is a semi quantitative, not exactly accurate method. In addition to measurement of total MGP levels, we recommend measurement of gammacarboxylated and uncarboxylated MGP forms. Despite this limitation, the results of the present study provide further evidence that vitamin $\mathrm{K}$ supplementation has a favorable effect on vascular calcifications.

\section{CONCLUSION}

Vitamin $\mathrm{K}$ supplementation could not stop aortic abdominal calcification and increasing in carotid intima media thickness, but significantly attenuate the progression of calcification; a longer treatment duration may prove significant amelioration of vascular calcification.

\section{FUNDING SOURCES}

This research received no grant from any funding agency in the public, commercial or not-for-profit sectors.

\section{REFERENCES}

[1] London G, Guerin A, Marchais S et al (2003) Arterial media calcification in end-stage renal disease: impact on all-cause and cardiovascular mortality. NDT 18(9):1731-1740.

[2] Noels, H.; Boor, P.; Goettsch, C.; Hohl, M.; Jahnen-Dechent, W.; Jankowski, V.; Kindermann, I.; Kramann, R.; Lehrke, M.; Linz, D.; et al. The new SFB/TRR219 Research Centre. Eur. Heart J. 2018, 39, 975-977.

[3] Kristen L. Jablonski, Ph.D. and Michel Chonchol: Vascular Calcification in End-Stage Renal Disease. Hemodial Int. 2013 Oct; 17(0 1): 10.1111/hdi.12084.

[4] Mizobuchi M, Towler D, Slatopolsky E: Vascular calcification: the killer of patients with chronic kidney disease. Journal of the American Society of Nephrology: JASN. 2009; 20:1453-1464.

[5] Shroff R, Long DA, Shanahan C: Mechanistic insights into vascular calcification in CKD. Journal of the American Society of Nephrology: JASN. 2013; 24:179-189.
[6] Schurgers, Barreto, Barreto, et al: The circulating inactive form of matrix Gla protein is a surrogate marker for vascular calcification in chronic kidney disease: a preliminary report. Clin J Am Soc Nephrol. 2010; 5:568-575.

[7] Holden, Hopman, Zimmerman, et al: Warfarin and aortic valve calcification in hemodialysis patients. J. Nephrol. 2007, 20, 417-422.

[8] Shanahan CM, Cary NR, Metcalfe JC, Weissberg PL: High expression of genes for calcification-regulating proteins in human atherosclerotic plaques. J Clin Invest. 1994; 93:2393-402.

[9] Tintut Y, Parhami F, Bostrom K, Jackson SM, Demer LL: cAMP stimulates osteoblast-like differentiation of calcifying vascular cells Potential signaling pathway for vascular calcification. J Biol Chem. 1998; 273:7547-53.

[10] Canfield AE, Doherty MJ, Kelly V, Newman B, et al: Matrix Gla protein is differentially expressed during the deposition of a calcified matrix by vascular pericytes. FEBS Lett. 2000; 487:267-71.

[11] Luo G, Ducy P, McKee MD, Pinero GJ, et al: Spontaneous calcification of arteries and cartilage in mice lacking matrix GLA protein. Nature. 1997; 386:78-81.

[12] Yao Y, Bennett BJ, Wang X, Rosenfeld ME, et al: Inhibition of bone morphogenetic proteins protects against atherosclerosis and vascular calcification. Circ Res. 2010; 107:485-94.

[13] Schurgers LJ, Spronk HM, Skepper JN, Hackeng TM, et al: Posttranslational modifications regulate matrix Gla protein function: importance for inhibition of vascular smooth muscle cell calcification. J Thromb Haemost. 2007; 5:2503-11.

[14] Price PA, June HH, Buckley JR, Williamson MK: Osteoprotegerin inhibits artery calcification induced by warfarin and by vitamin D. Arterioscler Thromb Vasc Biol. 2001;21:1610-6.

[15] Garred LJ, Barichello DL, DiGiuseppe B, McCready WG,et al: Simple $\mathrm{Kt} / \mathrm{V}$ formulas based on urea mass balance theory. ASAIO J 1994; 40:997-1004.

[16] Silaghi CN, Fodor D, Crăciun $\mathrm{AM}$ et al. Circulating matrix Gla protein: a potential tool to identify minor carotid stenosis with calcification in a risk population. Clin Chem Lab Med 2013; 51(5):1115-23

[17] Schousboe JT, Wilson KE, Hangartner TN. Detection of aortic calcification during vertebral fracture assessment (VFA) compared to digital radiography. Plos One. 2007; 2: e715-e9.

[18] Schurgers LJ, Teunissen KJ, Knapen MH, Kwaijtaal M, vanest R, et al: Novel conformation-specific antibodies against matrix gammacarboxyglutamic acid (Gla) protein: Undercarboxylated matrix Gla protein as marker for vascular calcification. Arterioscler Thromb Vasc Biol 2005; 25: 1629-1633.

[19] Churgers LJ, Barreto DV, Barreto FC, Liabeuf S, et al: The circulating inactive form of matrix Gla protein is a surrogate marker for vascular calcification in chronic kidney disease: A preliminary report. Clin J Am Soc Nephrol 2010; 5: 568-575.

[20] Schlieper G, Westenfeld R, Krüger $\mathrm{T}$ et al: Circulating Nonphosphorylated Carboxylated Matrix Gla Protein Predicts Survival in ESRD. JASN February 1, 2011; 22: 2 387-395.

[21] Rennenberg RJ, Schurgers LJ, Vermeer C, Scholte JB et al: Renal handling of matrix Gla-protein in humans with moderate to severe hypertension. Hypertens Res 2008; 31: 1745-1751.

[22] Schlieper, Aretz, Verberckmoes, et al: Ultrastructural analysis of vascular calcifications in uremia. J Am Soc Nephrol. 2011; 21: 689696.

[23] Hayashi M, Takamatsu I, Kanno Y, et al: A case-control study of calciphylaxis in Japanese end-stage renal disease patients. Nephrol Dial Transplant. 2012; 27: 1580-1584.

[24] Cranenburg EC, Koos R, Schurgers LJ, et al: Characterisation and potential diagnostic value of circulating matrix Gla protein (MGP) species. Thromb Haemost. 2010; 104: 811-822.

[25] Caluwe R, Vandecasteele S, Van Vlem B, et al: Vitamin K2 supplementation in haemodialysis patients: a randomized dosefinding study. Nephrol Dial Transplant. 2014; 29: 1385-1390.

[26] Beulens, J. W. Bots, M. L. Atsma, F. et al: High dietary menaquinone intake is associated with reduced coronary calcification. Atherosclerosis 2009. Apr; 203 (2): 489-93.

[27] Ketteler M, Bongartz P, Westenfeld R et al: Association of low fetuin A (AHSG) concentrations in serum with cardiovascular mortality in pa $\neg$ tients on dialysis: a cross-sectional study. Lancet 2003; 361:82733.

[28] Iwamoto J, Takeda T, Ichimura S. combined treatment with vitamin $\mathrm{K} 2$ and bisphosphonate in postmenopausal women with osteoporosis. Yonsei Med J 2003; 44:751-756.

[29] Khalil A and Youssef G. Protective effect of vitamin D\&K against arterial calcification in overectomized rats. Nat Sci 2013;11(12):239 246. 
[30] Cranenburg. The circulating inactive form of Matrix Gla Protein (ucMGP) as a biomarker for cardiovascular calcification. J Vase Res 2008; 45: 427^136.

[31] Parker, BD, Schurgers, LJ, Vermeer, C, et al: The association of uncarboxylated matrix Gla protein with mitral annular calcification differs by diabetes status: The Heart and Soul study. Atherosclerosis 2010:320-325

[32] Schurgers LJ, Teunissen KJ, Knapen MH, et al, Novel conformationspecific antibodies against matrix gammacarboxyglutamic acid (Gla) protein: undercarboxylated matrix Gla protein as marker for vascular calcification. Arterioscler Thromb Vasc Biol 2005 (25):1629- 1633.

[33] Shroff, Egerton, Bridel, et al: A bimodal association of vitamin D levels and vascular disease in children on dialysis. J Am Soc Nephrol 2008 c; 19: 1239-1246.

[34] Scheiber D, Veulemans V, Horn P, Chatrou M et al: Cardiovascular Calcification in a Murine Model of Extraosseous Calcification. Nutrients 2015, 7, 6991-7011.

[35] Sibal L, Agarwal S, Home P. Carotid intima-media thickness as a surrogate marker of cardiovascular disease in diabetes. Diabetes Metab Syndr Obes. 2011; 4: 23-34.

[36] Sathi S, Mahapatra H, Sunder S, Jayaraman R, Sharma N et al: Nontraditional Cardiovascular Biomarkers and Estimation of Cardiovascular Risk in Predialysis Chronic Kidney Disease Patients and Their Correlations With Carotid Intima Media Thickness. Nephrourol Mon. 2014; 6(6): e22112.

[37] Bellasi A, Raggi P. Vascular imaging in chronic kidney disease. Curr Opin Nephrol Hypertens 2012; 21: 382-388.

[38] Caluwé R, Pyfferoen L, Boeck K, and De Vriese A. The effects of vitamin $\mathrm{K}$ supplementation and vitamin $\mathrm{K}$ antagonists on progression of vascular calcification: ongoing randomized controlled trials. Clinical Kidney Journal, 2016; 9: (2) 273-279.

[39] Kurnatowska I, Grzelak P, Masajtis-Zagajewska A, et al: Effect of vitamin $\mathrm{K} 2$ on progression of atherosclerosis and vascular calcification in non-dialyzed patients with chronic kidney disease stages 3-5. Pol Arch Med Wewn. 2015; 125: 631-640.

[40] Gast GC, de Roos NM, Sluijs I, et al: A high menaquinone intake reduces the incidence of coronary heart disease. Nutr Metab Cardiovasc Dis.2009; 19: 504-510.

[41] Kona V, Yangb H, and Fazio S: Residual Cardiovascular Risk in Chronic Kidney Disease: Role of High-density Lipoprotein. Arch Med Res. 2015 July; 46(5): 379-391.

[42] Kawashima H, Nakajima Y, Matubara Y, Nakanowatari J et al Effects of vitamin K2 (menatetrenone) on atherosclerosis and blood coagulation in hypercholesterolemic rabbits. Jpn J Pharmacol. 1997; 75:135-143.

[43] Nagasawa Y, Fujii M, Kajimoto Y, Imai E, Hori M: Vitamin K2 and serum cholesterol in patients on continuous ambulatory peritoneal dialysis. Lancet. 1998; 351:724.

[44] Delanaye P, Krzesinski JM, Warling X, Moonen $M$ et al: Dephosphorylated-uncarboxylated Matrix Gla protein concentration is predictive of vitamin $\mathrm{K}$ status and is correlated with vascular calcification in a cohort of hemodialysis patients. BMC Nephrology 2014, 15:145.

[45] Leonard O, Spaak J, and Goldsmith D: Regression of vascular calcification in chronic kidney disease - feasible or fantasy? A review of the clinical evidence. Br J Clin Pharmacol. 2013 Oct; 76(4): 560572. 